\title{
REVSED Social prescribing for autistic people: A framework for
}

\section{service provision [version 2; peer review: 2 approved]}

\section{Rebecca A. Charlton (1D1, Catherine J. Crompton (D)2, Amanda Roestorf(iD3, Christopher Torry ${ }^{4,5}$, The Autistica Physical Health and Ageing Study Group}

\footnotetext{
${ }^{1}$ Department of Psychology, Goldsmiths University of London, London, SE14 6NW, UK

${ }^{2}$ Patrick Wild Centre, Division of Psychiatry, University of Edinburgh, Edinburgh, UK

${ }^{3}$ Department of Psychology, University of Stirling, Stirling, UK

${ }^{4}$ Surrey and Borders NHS Trust,, Leatherhead, Surrey, UK

5London Network of Nurses and Midwives Homelessness Group, London, UK
}

\author{
V2 First published: 27 Apr 2020, 2:19 \\ https://doi.org/10.12688/amrcopenres.12901.1 \\ Latest published: 12 Feb 2021, 2:19 \\ https://doi.org/10.12688/amrcopenres.12901.2
}

\section{Abstract}

Social Prescribing (SP) is the referral of patients to non-clinical services for practical, physical or psychosocial support. Recent guidelines from the National Health Service England mean that SP will become commonplace for people with complex healthcare needs. Autistic adults make up over $1 \%$ of the population and commonly have coexisting physical and mental health conditions, therefore they are likely to be referred to SP services. As yet, no studies have examined the efficacy of SP for autistic adults. In this letter, we review the existing literature examining the efficacy of SP in the general population. We further examine the factors that should be considered when offering SP to autistic adults in order to optimise outcomes for physical and mental well-being.

Keywords

Social prescribing, autism, complex health, personalised care

Open Peer Review
Approval Status
version 2
(revision)
12 Feb 2021
version 1
27 Apr 2020
...................................................................
1. Laura Crane (iD), University College London,
London, UK
2. Kenneth Larsen
Hospital, Oslo, Norway
Any reports and responses or comments on the
article can be found at the end of the article.


Corresponding author: Rebecca A. Charlton (r.charlton@gold.ac.uk)

Author roles: Charlton RA: Conceptualization, Writing - Original Draft Preparation, Writing - Review \& Editing; Crompton CJ:

Conceptualization, Writing - Original Draft Preparation, Writing - Review \& Editing; Roestorf A: Conceptualization, Writing - Original

Draft Preparation, Writing - Review \& Editing; Torry C: Conceptualization, Writing - Original Draft Preparation, Writing - Review \& Editing;

Competing interests: Amanda Roestorf is founder and director of Autism Awareness Ltd, a private organisation that provides CPD certified autism training for professionals and service providers who support autistic people. Chris Torry is a founding member of Autistic Community Brighton, who are a peer led group who organise events for autistic people, led by autistic people.

Grant information: UK Charity Autistica support and facilitate The Physical Health and Ageing Study Group. The funders had no role in study design, data collection and analysis, decision to publish, or preparation of the manuscript.

Copyright: (C) 2021 Charlton RA et al. This is an open access article distributed under the terms of the Creative Commons Attribution License, which permits unrestricted use, distribution, and reproduction in any medium, provided the original work is properly cited.

How to cite this article: Charlton RA, Crompton CJ, Roestorf A et al. Social prescribing for autistic people: A framework for service provision [version 2; peer review: 2 approved] AMRC Open Research 2021, 2:19 https://doi.org/10.12688/amrcopenres.12901.2

First published: 27 Apr 2020, 2:19 https://doi.org/10.12688/amrcopenres.12901.1 


\section{REVISED Amendments from Version 1}

Rationale for the paper and the lack of formal recommendations has been clarified, as has discussion relating to non-autism specific services. Discussion of impact of individual differences has been extended. References and resources have been added.

Any further responses from the reviewers can be found at the end of the article

\section{Introduction}

\section{General statement}

In January 2019, the National Health Service England (NHSE) launched a long-term plan for Universal Personalised Care (NHS England, 2019a; NHS England, 2019b; NHS England, 2019c). Universal Personalised Care aims to give people choices regarding their care, focusing on individual priorities and integrated approaches to better support individuals with multiple or complex health conditions. Social Prescribing (SP) is one crucial aspect of The Comprehensive Model of Universal Personalised Care that has been emphasised both by NHSE and by the Royal College of General Practitioners (NHSE, 2019a; Royal College of General Practitioners, 2018).

SP is the process by which health professionals refer patients to a range of non-clinical, community services. SP services and activities can include advocacy (support to access services such as housing or debt advice or to organise everyday activities), hobby activities (e.g. art, music or DIY), physical exercise, or psychosocial support groups. SP is intended to support but not replace formal healthcare resources such as psychiatric support and medical treatment. Under NHSE guidelines, SP is coordinated by a Link Worker. Usually, Link Workers are attached to general practice and may receive referrals from both the general practice and other external agencies. Their role is to connect people to community groups and agencies for practical and emotional support, and healthcare professionals when required (NHS England, 2019a). One study suggested that the Link Worker role is crucial to SP success, to help service users develop greater resilience, self-confidence and overall improved physical and mental health, whilst also reducing social isolation and risk of health-related relapse (Moffatt et al., 2017). In 2019, NHSE committed to recruiting 1,000 Link Workers by 2020/21 to support SP in primary healthcare settings (NHSE, 2019b, p. 25).

This paper will examine the factors affecting service provision for autistic ${ }^{1}$ people, describe potential barriers and gateways, and provide recommendations for supporting SP for autistic adults.

\footnotetext{
${ }^{1}$ In this article, we use 'identify-first' language (i.e. 'autistic person') rather than person-first language (i.e. 'person with autism'), because it is the preferred term of autistic activists (e.g., Sinclair, 1999) and many autistic people and their families (Kenny et al., 2016) and is less associated with stigma (Gernsbacher, 2017).
}

Importance and thesis statement

At least $1 \%$ of the general population is autistic (Baird et al., 2006; Brugha et al., 2016), meaning that in 2019, there are an estimated 660,000 autistic people in the UK. Autism is a lifelong condition often identified in childhood, although a diagnosis can occur later in the life-course (Happé \& Charlton, 2012). The core diagnostic criteria of autism include difficulties with social communication and repetitive behaviours and restricted interests (American Psychiatric Association, 2013). Social communication broadly describes how individuals interact with one another. Generally speaking, autistic people may have difficulties in processing verbal and non-verbal social communication, and in initiating, maintaining and navigating social communication. Executive function difficulties and sensory sensitivities are also common (Kenny et al., 2019; Lane et al., 2010).

Autism is a complex multi-faceted condition, with commonly cooccurring psychiatric, neurological and physical conditions (Bishop-Fitzpatrick \& Rubenstein, 2019; Joshi et al., 2013; Lever \& Geurts, 2016). Notably, rates of anxiety and depression are higher amongst autistic people than in the general population (Hudson et al., 2019; Lai et al., 2020). Recent research suggests that autistic people are at increased risk for many physical health conditions including cardiovascular disease, metabolic disorders, endocrine and immune conditions, and gastrointestinal disorders (Croen et al., 2015; Jones et al., 2015). Moreover, co-occuring mental and physical health conditions have been shown to impact the quality of life of autistic people (Mason et al., 2018). As autistic people often have multiple co-occurring physical and mental health conditions, they are likely to be amongst those referred to SP. However, very little is known about SP for autistic people - for example, it is unclear whether autistic people will benefit from such services, and what service characteristics might promote engagement and eventual "good outcomes". Although no formal evaluation of SP for autistic adults has yet been performed, there is evidence from individual studies that the types of activities offered in SP provision may be beneficial for SP support (Hesselmark et al., 2014). Further, we do not know whether services can self-monitor and adapt to the needs of autistic service users, and how they might incrementally improve the outcomes achieved.

\section{SP in the general population: evaluations and access}

There is anecdotal evidence that SP may be successful for a diverse range of (non-autistic) individuals but as yet there are few large scale independently-monitored trials that provide robust evidence for its efficacy (Pescheny et al., 2020). One randomised controlled trial of patients identified by their General Practitioner (GP) as having psychosocial problems demonstrated significant improvements in client levels of anxiety, general health, quality of life, and their ability to carry out everyday activities, but found no significant changes in depression or perceived social support (Grant et al., 2000). Two further qualitative studies describe widespread benefits to clients with long-term health conditions (Moffatt et al., 2017) and with mental health problems (Stickley \& Hui, 2012). However, a recent 
systematic review of SP states that while there is no clear evidence that SP is ineffective, there is also little evidence for its efficacy (Bickerdike et al., 2017). The lack of clear conclusions in that review is due to the small number of systematic studies published, the diversity of outcome measures reported and quality of evaluation methods (Bickerdike et al., 2017; Pescheny et al., 2020).

There is some evidence for efficacy. A scoping review suggests that SP is effective for improving patient outcomes (Thomson et al., 2015), and studies suggest it is cost-effective (Kimberlee, 2016; Polley et al., 2017a). Additionally, several service evaluations have been performed utilising both quantitative and qualitative data and describe generally positive responses to SP (Dayson \& Bennett, 2016a; Dayson \& Bennett, 2016b; Dayson et al., 2016; Kimberlee, 2013; Rose et al., 2018). These evaluations describe beneficial outcomes in social, psychological, and employment domains, and improvements in physical health behaviours; however, the mechanisms underlying the positive effects of SP are unclear. See Rates of uptake section below for evaluation details. However, the scoping review also identified diverse measures of outcomes following SP, including anxiety, depression, social isolation, exercise level and cost (Thomson et al., 2015). This diversity reflects the aims of SP services, the conditions or characteristics of individuals or client groups, and individual differences in desired outcomes. The most commonly assessed outcomes across 35 schemes were based on well-being (including mental well-being, $n=4$; and psychological well-being, which reflects anxiety and depression symptoms, $n=4$ ). The lack of a holistic or consistent measure of wellbeing, participation, or quality of life limits comparisons across studies. An appropriate way of measuring outcomes which will be comparable across individuals and services, may be to measure how well people feel they have moved towards their goals, thus enabling us to reflect individual differences in goal setting.

Despite there being relatively little research evaluating SP, many of the activities under this banner have long been used as interventions by charities and community organisations. Gardening clubs, exercise groups, art classes and choirs are often used to increase individual well-being, community engagement and social support. Such activities are often designed for specific groups by organisations aiming to support those groups; for example, older adults, people with addiction and/or mental health problems, carers, new mothers, etc. (Wilson \& Booth, 2015). While there is some research examining the efficacy of these individual activities (Clatworthy et al., 2013; Dingle et al., 2013), there are key differences between individual activities and SP more broadly. Firstly, routes to accessing these services might be formalised under SP and the effect of having a "prescription" for a defined activity, for a specified duration may impact uptake and maintenance. Secondly, a broader range of activities may be available via NHS SP, perhaps providing a better "fit" between patient and activity (for example, some organisations may specifically consider the impact of involvement in music but not offer support with functional skills, such as organising bills). Thirdly, activities may currently be offered to individuals with a certain characteristic (e.g., people with dementia, autistic people, etc.), whereas Link Workers may identify suitable services more generally. So far, current funding for SP seems focused on the recruitment of Link Workers to direct patients to appropriate existing services, impacting referral routes without funding for services themselves. The potential impact of increased referrals and more diverse patients to specific services is likely to affect existing service providers' ability to meet the needs of referred people, the availability of services offered and may raise issues related to staffing and resources.

Despite a broadly positive view from the small number of published papers and organisational reports, important limitations should also be noted. A recent systematic review of SP highlights that there is currently insufficient evidence to judge the success or value for money of SP (Bickerdike et al., 2017). The lack of clear conclusions from the review is due to the small number of systematic studies published, the heterogeneity of outcome measures reported and the variability in the quality of evaluations performed (Bickerdike et al., 2017; Pescheny et al., 2020). Furthermore, it is unclear what SP "dose" (frequency, duration and total number of sessions) will be effective. For these reasons there are not yet any clear recommendations for service provision or delivery of SP. The need for evidence to support best practice is clear. Any evidence produced must be compelling for those commissioning SP and be seen to meet their goals (Baker \& Irving, 2016). Further issues are described below.

\section{Rates of uptake}

Although SP has the potential to be beneficial for a wide range of people, successful implementation requires high levels of uptake and adherence among those who are prescribed social activities. There is no guarantee that individuals will be receptive to the services being offered for a variety of reasons, including the content of the activity, the practicalities of how and where it is delivered and how accessible it is to people with differing needs. The rates of uptake and adherence vary greatly across SP evaluations, as well as between clinical populations and providers. Among the general population (i.e., those with non-specific health difficulties), an evaluation in Doncaster reported uptake by $56 \%$ of those offered SP, whereas a similar service in Bristol reported uptake rates of $63-88 \%$ (Dayson \& Bennett, 2016b; Kimberlee, 2013). Although differences in these rates may reflect the options available at each location, they are also likely to reflect differences in characteristics of those being referred to services (Bickerdike et al., 2017; Natural England, 2017). Evidence for the importance of the individual's needs can be seen in evaluations from Rotherham, where uptake rates were $36 \%$ for individuals with long-term health conditions but $78 \%$ for individuals with secondary mental health problems (Dayson \& Bennett, 2016a; Dayson et al., 2016). It is important to note that the metric describing success or engagement in SP differs across studies, making comparisons difficult. Engagement figures often only reflect the individuals who agree to the initial referral, and rates may be lower if metrics include all individuals considered for SP but either 
not referred or not attending initial appointments (Bickerdike et al., 2017).

\section{General access issues}

The factors that influence engagement are not clear and are likely to reflect both differences in service characteristics (what is available), provisions for access (physical location, accessibility, direct and indirect costs), as well as differences in client characteristics, interests, and needs. For example, is a client with intellectual impairment living in supported accommodation as likely to be referred to a SP service as someone living independently without intellectual impairments? Even if both individuals were referred to SP, barriers to access are likely to be different. For an individual in supported living, a barrier may be the availability of carer to accompany the individual to an appointment, but the carer to make and at prompt to attend the appointment may be supportive. Different barriers and supports may exist for someone living independently. Many of these issues are similar for autistic people and a general population sample, therefore access issues will be described in detail in the subsequent section.

\section{Service provision of SP for autistic adults}

Service providers who work with autistic people need to demonstrate an understanding of the complexities of autism in everyday life and individual differences in interests, functional abilities and strengths/difficulties (Lai et al., 2020). Although some issues overlap with SP for the general population, some are specific to autism. It is therefore crucial that a basic level of autism awareness training is undertaken by Link Workers and services who provide for the needs of autistic service users (at least tier one of the Autism Capabilities Framework, Health Education England, 2019). Staff need to understand the wide range of autism symptoms and behaviour, that autistic people vary in their symptoms and needs, and to understand the everyday impact of additional demands relating to common co-occurring conditions. Understanding the diverse sociality of autistic people, and how social relationships are built and sustained by autistic people must be taken into account within SP settings. Successful SP services are likely to be those which enable autistic people to feel empowered, communicate their needs, and establish and maintain social relationships at their level of preference. SP services that take account of individual strengths and difficulties are more likely to effectively support autistic people across the lifespan and, therefore, deliver more long-term benefit (NICE, 2019). A factor to be considered will be the availability of SP provision. Autistic adults are most likely to be referred to existing services that support a wide range of people (e.g. a general walking group) or target people with a specific need (e.g. singing for older adults), rather than autism-specific services. However, services unfamiliar with autistic people may need to make adjustments in order to succeed.

Common co-occurring factors that impact daily life for autistic people are sensory sensitivities (Lane et al., 2010), anxiety and depression (Hudson et al., 2019; Lai et al., 2020), and difficulties in some aspects of executive function (Kenny et al., 2019). These co-occurring factors may cause specific barriers to accessing SP and services in general. Executive function is an umbrella term that describes goal-orientated behaviours such as planning, organisation and flexible thinking (Gioia et al., 2002). Executive function difficulties impact a range of everyday abilities, such as structuring activities and completing everyday tasks (e.g. planning and organising time, switching attention between tasks, etc). Moreover, executive function difficulties related to differences in processing information are often related to patterns of repetitive behaviours in autism. Hypo- or hyper-sensitivity (arousal) to sensory input (e.g. stark lighting, loud noise, etc) may manifest as an aversion to or avoidance of overwhelming sensory stimuli, or sensory seeking behaviours, such as hand-rubbing or tapping. In social situations, autistic people may use compensatory strategies to mask these sensory-related repetitive behaviours (Livingston \& Happe, 2017). "Masking" of autistic behaviours is related to significant mental distress, including depression (Cage et al., 2018) and suicidality (Cassidy et al., 2018) which may exacerbate existing high rates of co-occurring mental health conditions in autism (Hull et al., 2017).

\section{Referral}

A complex interplay of individual- and systemic-level barriers currently significantly reduce healthcare access for autistic people, which in turn could negatively impact access to SP (Nicolaidis et al., 2015). For instance, complex planning and communication are required to make appointments and navigate the healthcare system. Even making an appointment may present a barrier to autistic people due to difficulties using the phone (Benford \& Standen, 2009), and appointments are often too short to accommodate communication needs (Raymaker et al., 2017). Executive function difficulties are likely to further increase functional difficulties in planning, understanding and following complex instructions, and translating medical information into practical, achievable goals (Landa \& Goldberg, 2005; Raymaker et al., 2017). The sensory environment of clinics may cause significant discomfort to autistic people and impact their ability to communicate well or make tests and screenings difficult (Raymaker et al., 2017). Autistic adults may have difficulty in communicating their concerns to clinicians. However, clinician knowledge of autism, particularly in adulthood and for those with co-occurring mental health conditions, is generally low (Camm-Crosbie et al., 2019; Dern \& Sappock, 2016; Raymaker et al., 2017). Moreover, the stigma associated with autism (Nicolaidis et al., 2015) and incorrect assumptions that autistic people do not want social interaction with others (Jaswal \& Akhtar, 2019) may result in clinicians assuming that autistic adults may not benefit from SP, directly impacting SP referral options.

Whilst SP is a promising intervention for autistic people, providers should take account of all we have learnt from the challenges autistic people experience when accessing a 'one size fits all' model of health care. Due to previous negative experiences in healthcare settings, some autistic adults may not seek referral or support via their GP, and therefore SP for autistic people may be best provided through existing autism support services. Autism training for healthcare staff, including Link Workers should focus on the attitudes, skills and environment required to 
provide effective healthcare to autistic people (Nicolaidis et al., 2015), and should adhere to at least tier one of the Autism Capabilities Framework (Health Education England, 2019). Autism-knowledgeable Link Workers should manage a referral that fits the need of the autistic person and enables them to access SP services prescribed by overcoming practical or communicative barriers. There is a growing awareness that autistic-led organisations and groups can provide exceptional support in an environment that many autistic individuals find comfortable. Where possible, signposting to or integrating with an existing advocacy service (whether specific to autistic individuals or related to a specific mental health issue) may provide the best outcomes and cost-benefit scenarios.

Identifying a regular or routine activity or type of support that an individual can engage with positively is a vital initial step. For an autistic person, selecting an activity may require additional consideration of sensory or physical issues; for example, it may be unsuitable to refer someone highly sensitive to sounds to an orchestra programme. An open discussion with each individual about their likes, dislikes and sensory issues before referrals may reduce attrition. Good practice would be to systematically ask people about any sensory issues or routinely utilise an existing sensory questionnaire (e.g., The Glasgow Sensory Questionnaire is freely available; see Robertson \& Simmons, 2013).

An effective referral could be facilitated by a 'service passport', which may be especially useful for autistic people with complex health profiles. This could be a simple document designed to support autistic individuals when accessing health and social care services who have difficulties advocating for themselves. The resulting information would provide a summary of co-existing diagnoses and related conditions or difficulties associated with autism, such as sensory sensitivities, motor function limitations, basic cognitive difficulties and issues related to social communication. A service passport could help customise SP referrals to services that are appropriate to the autistic person, in line with their individual needs. It would also potentially facilitate a method of reviewing the efficacy of services provided or highlight the need for referrals back into primary care settings, as required. Guidelines for service assessments exist such as those by the South-West Yorkshire NHS Trust and the Autism Healthcare Accommodations Tool which produces individualised reports describing communication preferences (https://autismandhealth.org/; Nicoladis et al., 2016). Although the checklists referred to here suggest that they should be completed individually and with pen and paper, it is important to be flexible in how information is collected and to cater to the preference of individual clients. These checklists can be administered as interviews in person or over the phone, or through a pen and paper response.

What is not yet clear, is how potential issues relating to successful or unsuccessful interventions will be managed in the early and later stages of SP provision. How many options will an individual have to choose from? How many attempts to find an appropriate intervention are acceptable? An additional issue may be if a person refuses SP due to either dissatisfaction with resources offered or difficulty engaging in a group activity. Many autistic people find group situations difficult, and the prospect of attending a group activity may be initially overwhelming even if over time activities become positive. One can easily imagine a scenario where an initial SP activity is unsuccessful for a range of reasons, due to physical or environmental demands being too great for an individual or group dynamics. In this scenario, the process for a change to the referred activity or the number of "attempts" an individual has to find a suitable intervention is not clear. A realistic view of NHS services suggests that opportunities will be limited, therefore there may be a punitive element associated with an unsuccessful referral, although those individuals most at risk for unsuccessful initial referrals may be those whose need is greatest.

\section{Access}

Understanding the potential environmental and individual factors that may make it difficult for autistic people to attend SP activities is vital to successful service provision. Difficulties with novel social interactions and anxiety when facing an unfamiliar environment and people may reduce the likelihood of attending initial contact visits. Initial appointments for accessing SP activities require executive function abilities (to prepare for and initiate attendance), social communication (interacting with new people), and overcoming anxiety to both attend and continue attending.

Prior to the first visit to any activity, clear guidelines about what to expect may help to reduce anxiety. Pre-visit support by the Link Worker should include a plain language information leaflet detailing what to expect, the schedule of events, and expectations about appointments. A description of the physical location of the session including photographs and a map or schematic of the location may also be included. It may be helpful for someone who knows the individual, either the SP Link Worker or a friend to accompany the referee for the first visit to help reduce anxiety and offer support if required. Additional information about the timeline of visits, number and frequency of sessions, planned interruptions (i.e. during holidays etc.), any transitions to new environments, activities or staff changes, or the end of the visits should be provided as soon as possible.

Once in attendance, the physical environment (lighting, noise, smell or other environmental factors) will be an obstacle for some autistic people due to common sensory sensitivities. Differences in sensory processing are commonly associated with autism, but the degree of sensitivity varies widely between autistic people. Specific difficulties can lead to 'hyper-focusing' or difficulties responding to relevant information, as well as avoidance behaviours, increased inflexibility, and 'meltdown' or 'shutdown' responses (Ashburner et al., 2013). Coping mechanisms for dealing with sensory difficulties are personal to the individual, but these difficulties can affect how the individual interacts with unpredictable environments (Ashburner et al., 2013). SP activities often occur in community settings where organisers have little control over the physical environment. Even within a setting with low sensory distractions, group activities may temporarily change the environment (e.g., increase noiselevels) leading to people becoming overwhelmed. Where 
possible, lighting should be adjustable and strip-lighting should be avoided. When this is not possible individual adjustments (e.g., use of shaded spectacles or sunglasses) should be encouraged and accepted. Likewise, the use of noise-cancelling headphones and other individual adjustments should be accommodated. Where possible, a quiet room or breakout room should be available. This does not need to be a large space but should simply be a room where individuals can take some time on their own to relax should an appointment become overwhelming.

Fellow clients in SP settings may be unfamiliar with autism, therefore acceptance of individual differences needs to be embedded within SP. One can easily imagine a scenario where an initial SP activity is unsuccessful due to group dynamics making an individual feel unwelcome despite efforts by staff. If autistic people feel that they must "mask" their true-selves or behaviours (e.g. repetitive behaviours) to blend into a social group, this may lead to heightened anxiety and reduce meaningful social interactions (Cage et al., 2018). Further, autistic people may want to be sociable but find it difficult to initiate interactions due to anxiety, social communication or executive function difficulties. It is worth clarifying here that we are providing guidance for ways that SP provisions can support a range of clients including autistic adults, rather than suggesting autism-specific services. There are several reasons for this. We have already questioned the potential availability of different services within a local community. Access to a general community SP service that supports individuals with complex needs may be more suitable than a restricted autism-specific offering or one that is outside the local area. Although a number of studies have found that services led by autistic individuals can be beneficial for autistic adult outcomes (e.g. Rosqvist, 2019; Crane et al., 2020), it is important to avoid isolating autistic adults into silos. SP services should ensure that they are accessible to whomever wishes to access them, and we suggest that general services which accept and support neurodiversity may have the greatest impact on the well-being of autistic adults. Autistic self-advocates, autism charities and organisations working with autistic individuals can provide advice about developing and running services. Link workers and SP services can benefit by partnering with existing organisations who may have experience working with autistic adults (or autistic adults themselves) and incorporating their advice and expertise. This partnering may lead to the most successful outcomes for minimal expenditure.

\section{Setting goals and measuring outcomes}

There is a lack of clarity in the optimum measure for achieving goals or SP "success". What are the expectations of a Socially Prescribed activity (for the referrer or participant), and are these the same for all individuals? "Success" will likely differ for each individual, depending on the reason for initial referral. Well-being has been the most commonly assessed measure of SP success, but may not always be appropriate, either for the activity or the primary goal.

Due to this variability, it may be reasonable for each individual to set their own (realistic) goals with a Link Worker before referral, and to assess to what extent they have been achieved at set periods. Where longer-term goals are set, they may be achieved outside the timeframe of the SP and goals will need careful monitoring as they may change over time or follow a non-linear trajectory. Although this approach will lead to individual differences in goals themselves, there will be consistency in "achievement" ratings which may allow comparison across individuals, groups, and activities. This may also overcome limitations of measures not being suitable for use with autistic people. Of course, individuals are likely to differ in their rates of change or timeline for achieving their goals, and it will be important to allow for these differences in any measures of "success".

There are also potential issues relating to the "success" of an activity or intervention. Presuming that an individual has achieved their goals, the NHS model would be to discharge an individual from accessing services. Indeed, discharge from services has been used as an outcome measure in previous evaluations (Dayson \& Bennett, 2016a). SP activities are likely to support an individual in multiple ways, i.e., skill development, social support, assistance with physical and mental health, therefore the impact of removing this support by discharging from services is not clear. For autistic people in particular who may have a strong need for routines and structure, a sudden discharge from a regular service providing support may be detrimental to well-being and long-term outcomes. However, it is unrealistic to expect SP activities, many run by charities and community organisations, to be sustained without guaranteed financial support. There is a risk therefore, that successful SP may also create risks for its long-term viability.

\section{Discussion}

The provisions of NHSE's Comprehensive Universal Personalised Care will make SP a realistic and potential option for primary healthcare providers. There is some evidence that SP is effective for those with complex medical and psychiatric needs. However, there have been no systematic evaluations of the suitability of services for autistic people. Given that autistic people often experience multiple co-occurring physical and mental conditions, they are likely to be referred to SP services. For SP to have a meaningful impact for autistic people it needs to be effective, accessible, and acceptable. Autistic people have specific needs that may be difficult to incorporate into SP but could be accommodated with small and low-cost person-centred adjustments.

With SP being integrated into every General Practice in England, more robust and systematic measures of outcomes will be necessary for effective service evaluation. The way that the efficacy of SP is measured for autistic people may require additional consideration in line with autistic experience. Qualitative studies can explore the experiences of SP for autistic people and interrogate both barriers and facilitators for success. Using measures that are flexible to different individual goals, rather than an arbitrarily selected measure that is designed for use in the general population, will allow meaningful evaluation across different services and autistic people (Polley et al., 2017b). 
SP provides a real opportunity for positive impact with the autistic population. Social interaction may improve autistic people's mental health (Cage et al., 2018; Mazurek, 2014) and facilitate physical activity (Pan, 2009). SP can provide a daily or weekly routine which may be beneficial for autistic people who may find this structure helpful. To make SP effective for autistic people, it must be tailored to their individual needs and incorporate their strengths. Systematic barriers for autistic people to routine healthcare need to be addressed, as do barriers to SP providers in order to maximise the equitability of these services and SP options. As SP becomes widespread across NHSE, research is required to evaluate the efficacy of SP generally and for autistic people specifically. As evidence accumulates it will be possible to develop guidelines for best practice for supporting autistic people to achieve their self-identified goals.

\section{Data availability}

No data are associated with this article.

\section{Acknowledgements}

The Autistica Physical Health and Ageing Study Group comprises Debbie Allen, Bryony Beresford, Carole Buckley, Rebecca A. Charlton, Catherine J. Crompton, Jane Cumming, Mihalis Doumas, Lorcan Kenny, Lucy A. Livingston, Jeremy Parr, Amanda Roestorf, Chris Torry, Colin Wilson.

\section{Disclaimer}

The views expressed in this article are those of the author(s). Publication in AMRC Open Research does not imply endorsement by the AMRC.
American Psychiatric Association: Diagnostic and Statistical Manual of Mental Disorders (DSM-5®). American Psychiatric Publishers, 2013. Reference Source

Ashburner J, Bennett L, Rodger S, et al.: Understanding the sensory experiences of young people with autism spectrum disorder: A preliminary investigation. Aust Occup Ther 1. 2013; 60(3): 171-180.

PubMed Abstract | Publisher Full Text

Baird G, Simonoff E, Pickles A, et al.: Prevalence of disorders of the autism spectrum in a population cohort of children in South Thames: the Special Needs and Autism Project (SNAP). Lancet. 2006; 368(9531): 210-215. PubMed Abstract | Publisher Full Text

Baker K, Irving A: Co-producing Approaches to the Management of Dementia through Social Prescribing. Social Policy \& Administration. 2016; 50(3): 379-397.

Publisher Full Text

Rosqvist HB: Knowing what to do: exploring meanings of development and peer support aimed at people with autism. International Journal of Inclusive Education. 2019: 23(2): 174-187.

Publisher Full Text

Benford P, Standen PJ: The Internet: A comfortable communication medium for people with Asperger syndrome (AS) and high functioning autism (HFA)? J Assist Technol. 2009; 3(2): 44-53.

Publisher Full Text

Bickerdike L, Booth A, Wilson PM, et al.: Social prescribing: less rhetoric and more reality. A systematic review of the evidence. BMJ Open. 2017; 7(4): e013384.

PubMed Abstract | Publisher Full Text | Free Full Text

Bishop-Fitzpatrick L, Rubenstein E: The physical and mental health of middle aged and older adults on the autism spectrum and the impact of intellectual disability. Res Autism Spectr Disord. 2019; 63: 34-41.

PubMed Abstract | Publisher Full Text | Free Full Text

Brugha TS, Spiers N, Bankart J, et al.: Epidemiology of autism in adults across age groups and ability levels. BrJ Psychiatry. 2016; 209(6): 498-503. PubMed Abstract | Publisher Full Text

Cage E, Di Monaco J, Newell V: Experiences of autism acceptance and mental health in autistic adults. J Autism Dev Disord. 2018; 48(2): 473-484. PubMed Abstract | Publisher Full Text | Free Full Text

Camm-Crosbie L, Bradley L, Shaw R, et al.: 'People like me don't get support': Autistic adults' experiences of support and treatment for mental health difficulties, self-injury and suicidality. Autism. 2019; 23(6): 1431-1441. PubMed Abstract | Publisher Full Text | Free Full Text

Cassidy $S$, Bradley $L$, Shaw $R$, et al:: Risk markers for suicidality in autistic adults. Mol Autism. 2018: 9: 42

PubMed Abstract | Publisher Full Text | Free Full Text

Clatworthy J, Hinds J, Camic PM: Gardening as a mental health intervention: a review. Ment Health Rev J. 2013; 18(4): 214-225.

Publisher Full Text

Crane L, Hearst C, Ashworth M, et al.: Supporting Newly Identified or Diagnosed Autistic Adults: An Initial Evaluation of an Autistic-Led Programme. J Autism Dev Disord. 2020; 1-14.

PubMed Abstract | Publisher Full Text
Croen LA, Zerbo O, Qian $Y$ et al: The health status of adults on the autism spectrum. Autism. 2015; 19(7): 814-823.

PubMed Abstract | Publisher Full Text

Dayson C, Bashir N, Bennett E, et al.: The Rotherham Social Prescribing Service for People with Long-Term Health Conditions, Summary Report. Sheffield: Centre for Regional Economic and Social Research, 2016. Reference Source

Dayson C, Bennett E: Key Findings from the Evaluation of the Rotherham Mental Health Social Prescribing Pilot. Sheffield: Centre for Regional

Economic and Social Research, 2016a.

Reference Source

Dayson C, Bennett E: Evaluation of Doncaster Social Prescribing Service: understanding outcomes and impact. Sheffield: Centre for Regional Economic and Social Research, 2016b.

Reference Source

Dern S, Sappok T: Barriers to healthcare for people on the autism spectrum Advances in Autism. 2016; 2(1): 2-11.

Publisher Full Text

Dingle GA, Brander C, Ballantyne J, et al:: 'To be heard': The social and menta health benefits of choir singing for disadvantaged adults. Psychol Music. 2013; 41(4): 405-421.

Publisher Full Text

Gernsbacher MA: Editorial perspective: The use of person-first language in scholarly writing may accentuate stigma. / Child Psychol Psychiatry. 2017; 58(7): 859-861.

PubMed Abstract | Publisher Full Text | Free Full Text

Gioia GA, Isquith PK, Kenworthy L, et al.: Profiles of everyday executive function in acquired and developmental disorders. Child Neuropsychol. 2002; 8(2): 121-137.

PubMed Abstract | Publisher Full Text

Grant $\mathrm{C}$, Goodenough $\mathrm{T}$, Harvey I, et al: A randomised controlled trial and economic evaluation of a referrals facilitator between primary care and the voluntary sector. $B M J$. 2000; 320(7232): 419-23.

PubMed Abstract | Publisher Full Text | Free Full Text

Happé $F$, Charlton RA: Aging in autism spectrum disorders: a mini-review. Gerontology. 2012; 58(1): 70-78.

PubMed Abstract | Publisher Full Text

Health Education England: Core Capabilities Framework for Supporting Autistic People. Department for Health \& Social Care, 2019.

Reference Source

Hesselmark E, Plenty S, Bejerot S: Group cognitive behavioural therapy and group recreational activity for adults with autism spectrum disorders: A preliminary randomized controlled trial. Autism. 2014; 18(6): 672-683. PubMed Abstract | Publisher Full Text | Free Full Text

Hudson CC, Hall L, Harkness KL: Prevalence of depressive disorders in individuals with autism spectrum disorder: A meta-analysis. J Abnorm Child Psychol. 2019; 47(1): 165-175.

PubMed Abstract | Publisher Full Text

Hull L, Petrides KV, Allison C, et al.: "Putting on my best normal": social camouflaging in adults with autism spectrum conditions. J Autism Dev 
Disord. 2017; 47(8): 2519-2534.

PubMed Abstract | Publisher Full Text | Free Full Text

Jaswal VK, Akhtar N: Being vs. appearing socially uninterested: Challenging assumptions about social motivation in autism. Behav Brain Sci. 2019; 42: 1-84, e82.

PubMed Abstract | Publisher Full Text

Jones KB, Cottle K, Bakian A, et al.: A description of medical conditions in adults with autism spectrum disorder: A follow-up of the 1980s Utah/UCLA Autism Epidemiologic Study. Autism. 2015; 20(5): 551-561.

PubMed Abstract | Publisher Full Text

Joshi G, Wozniak J, Petty C, et al.: Psychiatric comorbidity and functioning in a clinically referred population of adults with autism spectrum disorders: a comparative study. J Autism Dev Disord. 2013; 43(6): 1314-1325.

PubMed Abstract | Publisher Full Text

Kenny L, Cribb SJ, Pellicano E: Childhood executive function predicts later autistic features and adaptive behavior in young autistic people: A 12-year prospective study. J Abnorm Child Psychol. 2019; 47(6): 1089-1099.

PubMed Abstract | Publisher Full Text

Kenny L, Hattersley $C$, Molins $B$, et al: Which terms should be used to describe autism? Perspectives from the UK autism community. Autism. 2016: 20(4): 442-462.

PubMed Abstract | Publisher Full Text

Kimberlee RH: Developing a Social Prescribing approach for Bristol. Bristol:

Faculty of Health and Life Sciences. 2013.

Reference Source

Kimberlee R: What is the value of social prescribing? Adv Soc Sci Res J.

2016; 3(3)

Publisher Full Text

Lai MC, Anagnostou E, Wiznitzer M, et al.: Evidence-based support for autistic people across the lifespan: maximising potential, minimising barriers, and optimising the person-environment fit. Lancet Neurol. 2020;

pii: S1474-4422(20)30034-X.

PubMed Abstract | Publisher Full Text

Landa RJ, Goldberg MC: Language, social, and executive functions in high functioning autism: a continuum of performance. J Autism Dev Disord. 2005; 35(5): 557-73.

PubMed Abstract | Publisher Full Text

Lane $A E$, Young RL, Baker AE, et al.: Sensory processing subtypes in autism: association with adaptive behavior. J Autism Dev Disord. 2010; 40(1): 112-122. PubMed Abstract | Publisher Full Text

Lever AG, Geurts HM: Psychiatric Co-occurring Symptoms and Disorders in

Young, Middle-Aged, and Older Adults with Autism Spectrum Disorde

| Autism Dev Disord. 2016; 46(6): 1916-1930.

PubMed Abstract | Publisher Full Text | Free Full Text

Livingston LA, Happé F: Conceptualising compensation in

neurodevelopmental disorders: Reflections from autism spectrum

disorder. Neurosci Biobehav Rev. 2017; 80: 729-742.

PubMed Abstract | Publisher Full Text

Mason D, McConachie $\mathrm{H}$, Garland D, et al: Predictors of quality of life for

autistic adults. Autism Res. 2018; 11(8): 1138-1147.

PubMed Abstract | Publisher Full Text | Free Full Text

Mazurek MO: Loneliness, friendship, and well-being in adults with autism

spectrum disorders. Autism. 2014; 18(3): 223-232.

PubMed Abstract | Publisher Full Text

Moffatt S, Steer M, Lawson S, et al.: Link Worker social prescribing to improve health and well-being for people with long-term conditions: qualitative study of service user perceptions. BMJ Open. 2017; 7(7): e015203. PubMed Abstract | Publisher Full Text | Free Full Text

Natural England: Good practice in social prescribing for mental health: the role of nature-based interventions (NECR228). Natural England UK. 2017.

Reference Source
NHS England: Social prescribing and community-based support: Summary guide. UK: NHS England. 2019a.

Reference Sourc

NHS England: The NHS Long Term Plan. UK: NHS England. 2019b. Reference Source

NHS England: Universal Personalised Care: Implementing the

Comprehensive Model. UK: NHS England. 2019c.

Reference Source

NICE Guidelines: People with dementia should be offered activities that can help promote wellbeing. 2019.

Reference Source

Nicolaidis C, Raymaker DM, Ashkenazy E, et al.: "Respect the way I need to communicate with you": Healthcare experiences of adults on the autism spectrum. Autism. 2015; 19(7): 824-831.

PubMed Abstract | Publisher Full Text | Free Full Text

Nicoladis C, Raymaker DM, McDonald K, et al.: The development and evaluation of an online healthcare toolkit for autistic adults and their primary care providers. J Gen Intern Med. 2016; 31(10): 1180-9.

PubMed Abstract | Publisher Full Text | Free Full Text

Pan CY: Age, social engagement, and physical activity in children with autism spectrum disorders. Research in Autism Spectrum Disorders. 2009; 3(1): 22-31.

Publisher Full Text

Pescheny JV, Randhawa G, Pappas Y: The impact of social prescribing services on service users: a systematic review of the evidence. Eur J Public Health. 2020; 30(4): 664-673.

PubMed Abstract | Publisher Full Text

Polley $\mathrm{M}$, Bertotti M, Kimberlee R, et al:: A review of the evidence assessing impact of social prescribing on healthcare demand and cost implications. London: University of Westminster. 2017a.

Reference Source

Polley C, Fleming J, Anfilogoff T, et al.: Making sense of Social Prescribing. London: University of Westminster. 2017b.

Reference Source

Raymaker DM, McDonald KE, Ashkenazy E, et al: Barriers to healthcare: Instrument development and comparison between autistic adults and adults with and without other disabilities. Autism. 2017; 21(8): 972-984. PubMed Abstract | Publisher Full Text | Free Full Text

Robertson $A E$, Simmons DR: The relationship between sensory sensitivity and autistic traits in the general population. J Autism Dev Disord. 2013; 43(4): $775-784$

PubMed Abstract | Publisher Full Tex

Rose C, Rankin S, Seale B, et al:: Unleashing Healthy Communities, Full Report Researching the Bromley by Bow model. London: Bromley by Bow Insights. 2018.

Reference Source

Royal College of General Practitioners: Spotlight on 10 High Impact Actions. London, UK: Royal College of General Practitioners. 2018.

Reference Source

Sinclair J: Why I dislike 'person-first' language. Jim Sinclair's website. 1999; (accessed 9 October 2019).

Reference Source

Stickley T, Hui A: Social prescribing through arts on prescription in a U.K. city: participants' perspectives (part 1). Public Health. 2012; 126(7): 574-579. PubMed Abstract | Publisher Full Text

Thomson LJ, Camic PM, Chatterjee HJ: Social Prescribing: A review of community referral schemes. London: University College London. 2015. Reference Source

Wilson $P$, Booth A: Evidence to inform the commissioning of social prescribing. York: Centre for Reviews and Dissemination. 2015.

Reference Source 


\section{Open Peer Review}

\section{Current Peer Review Status:}

\section{Version 2}

Reviewer Report 04 May 2021

https://doi.org/10.21956/amrcopenres.14047.r26627

(C) 2021 Crane L. This is an open access peer review report distributed under the terms of the Creative Commons Attribution License, which permits unrestricted use, distribution, and reproduction in any medium, provided the original work is properly cited.

\section{Laura Crane}

Institute of Education, University College London, London, UK

As per my original review, I am very positive about the topic of this letter. I also appreciate the authors' response to my original comments. I have no further suggestions to make.

Competing Interests: No competing interests were disclosed.

Reviewer Expertise: autism, education, healthcare (diagnosis, mental health), participatory research

I confirm that I have read this submission and believe that I have an appropriate level of expertise to confirm that it is of an acceptable scientific standard.

Reviewer Report 10 March 2021

\section{https://doi.org/10.21956/amrcopenres.14047.r26626}

(C) 2021 Larsen K. This is an open access peer review report distributed under the terms of the Creative Commons Attribution License, which permits unrestricted use, distribution, and reproduction in any medium, provided the original work is properly cited.

\section{Kenneth Larsen}

Division of Pediatric and Adolescent Medicine, Regional Resource Centre for Autism, ADHD, Tourette's Syndrome and Narcolepsy, Oslo University Hospital, Oslo, Norway

I find the revisions appropriate.

Competing Interests: No competing interests were disclosed. 


\section{I confirm that I have read this submission and believe that I have an appropriate level of expertise to confirm that it is of an acceptable scientific standard.}

\section{Version 1}

Reviewer Report 19 October 2020

https://doi.org/10.21956/amrcopenres.13971.r26569

(C) 2020 Larsen K. This is an open access peer review report distributed under the terms of the Creative Commons Attribution License, which permits unrestricted use, distribution, and reproduction in any medium, provided the original work is properly cited.

\section{Kenneth Larsen}

Division of Pediatric and Adolescent Medicine, Regional Resource Centre for Autism, ADHD, Tourette's Syndrome and Narcolepsy, Oslo University Hospital, Oslo, Norway

Thank you for the opportunity to review this letter on Social prescribing for adults with Autism Spectrum Disorder. This is an important area of service provision were the scientific study is scarce (if any), and I commend the authors for bringing this topic to the scientific discussion.

The letter is clearly and accurately presented, and cite relevant literature as far as the topics discussed.

I have some comments that may be useful for the authors in further discussing this topic.

\section{The autism-focus}

The letter uses a large portion on discussing the efficacy of social prescribing in the general population, as stated later social prescribing needs to be tailored to the challenges of people with autism spectrum disorder. This makes me question whether this thorough review is necessary for this letter.

Autism Spectrum Disorders are as mentioned a heterogeneous condition, and I think the letter should in greater depth especially discuss the variation in adaptive behavior and cognitive level, and how this variation may be related to social prescribing.

\section{The recommendation}

The letter discusses challenges that may affect people with Autism Spectrum Disorders, and possible measures that may facilitate social prescribing. However this could preferable be more specific and detailed.

Competing Interests: No competing interests were disclosed.

Reviewer Expertise: Autism Spectrum Disorders, education, service delivery, early identification 


\title{
I confirm that I have read this submission and believe that I have an appropriate level of expertise to confirm that it is of an acceptable scientific standard, however I have significant reservations, as outlined above.
}

Author Response 29 Jan 2021

Rebecca Charlton, Goldsmiths University of London, London, UK

\section{Response to Reviewer 2}

We thank the reviewer for their positive and helpful comments. Regarding the issue of whether the focus should include the general population or autism only. The inclusion of information relating to the general population is required, as studies are limited and most evidence of formal Social Prescribing comes from studies in the general population. That being said, with the development of Social Prescribing as part of NHS Universal Personalised Care in England, such services are likely to be offered to autistic adults due to their relatively high level of complex needs as a group. While Social Prescribing may be beneficial for autistic adults, characteristics of services may reduce uptake among these individuals. The purpose of the paper is to raise awareness of issues relating to the need for evidence for Social Prescribing and accommodations that may be required to support a wide range of individuals.

Many thanks for the comment relating to different individual differences and functional level. We have added information relating to this point, in terms of who may be referred to Social Prescribing and the barriers for different individuals.

We have also clarified the reason for lack of specific details and recommendations, namely that evidence to support such recommendations is limited.

Competing Interests: No competing interests were disclosed.

Reviewer Report 19 May 2020

https://doi.org/10.21956/amrcopenres.13971.r26483

(C) 2020 Crane L. This is an open access peer review report distributed under the terms of the Creative Commons Attribution License, which permits unrestricted use, distribution, and reproduction in any medium, provided the original work is properly cited.

\author{
Laura Crane \\ Institute of Education, University College London, London, UK
}

Thank you for the opportunity to review this crucially important letter on social prescribing for autistic adults. I would like to commend the authors for submitting (what I believe to be) the firstever academic publication on this topic.

In terms of the review criteria, the authors have done exceptionally well to outline the rationale for the letter, write in clear and accessible language, and use existing evidence to support their statements (all of which appear factually accurate). 
Below, I have outlined some aspects that I hope will be useful for the authors in further strengthening this valuable contribution to the literature. With reference to the review criteria, these centre on making recommendations and next steps clearer for others to follow and providing more in-depth discussions of differing views and opinions.

\section{1) The need to make the letter more consistently autism-specific}

Currently, this letter is structured around two aims: (1) "reviewing the existing literature examining the efficacy of social prescribing in the general population", and (2) "examining the factors that should be considered when offering SP to autistic adults in order to optimise outcomes". I was not totally convinced of the need for aim one. The authors reference a systematic review on social prescribing by Bickerdike et al. (2017) $)^{1}$ and none of the studies referenced in this letter seem to post-date this review. It may be more useful for the authors to start their letter by giving a short definition of social prescribing, before structuring the letter around different aspects of social prescribing (e.g., referral, access). Within each section, they could provide a very brief overview of what we know generally (i.e., what standard/good practice is) before largely focusing on how social prescribing services might need to adapt to better accommodate the needs of autistic adults. This would make the letter more focused and impactful.

\section{2) The need for deeper discussions around broader issues}

The authors do a good job of explaining the ways in which social prescribing might need to be adapted for autistic people, but I felt two key points needed to be addressed before this was discussed.

First, based on what we know from the available literature, is it likely that social prescribing would be useful for autistic adults? The authors imply that this is the case ("...SP is a promising intervention for autistic people..."), but there needs to be an evidence-base cited to support this assertion. As one example from my own work, there is initial evidence on the benefits of psychosocial support groups for autistic people (Crane et al., 2020) ${ }^{2}$.

Second, should there be autism-specific/autistic-led social prescribing services? I appreciate the authors noting how autistic adults are most likely to be referred to existing social prescribing services (rather than those specifically designed for autistic adults), yet this doesn't mean that this shouldn't be discussed and debated. The fascinating work on autistic-autistic/autistic-neurotypical interactions by Crompton et al. $(2020)^{3}$ would be very relevant here, and might imply that service provision should, indeed, be autism-specific. And the aforementioned work on psychosocial support groups (Crane et al., 2020) ${ }^{2}$ suggests that it could benefit from being autistic-led too.

\section{3) The need for more explicit recommendations and next steps}

I was very much in agreement with the majority of the authors' recommendations for adapting social prescribing services for autistic adults. However, I did wonder whether these needed to be clearer and more explicit; at the end of each section and/or in the final discussion. There is a lot of information presented in the article, so drawing out the key priorities is really important. I was also surprised that there wasn't greater mention of the need to involve autistic people themselves in discussions about social prescribing (especially about service design and delivery). Previous work (e.g., Crane et al., 2019) ${ }^{4}$ has identified this as crucially important with regards to healthcare. 


\section{4) Other, minor suggestions}

a) I would recommend that the title is edited to refer to 'autistic adults' rather than 'autistic people' (as children are not addressed within the review).

b) In the first paragraph of 'Importance and thesis statement', I think the paragraph could be ended after the APA (2013) citation. It is unclear why, for example, executive function difficulties and sensory sensitivities are mentioned - there are a wide range of autistic characteristics that could be mentioned here, and it perhaps makes more sense to give the diagnostic criteria for autism rather than selecting some autistic characteristics but not others.

c) I was unsure of the relevance of the paragraph starting "Common co-occurring factors that impact daily life for autistic people are...". This descriptive information may be useful for those unfamiliar with autism, but should be better integrated within recommendations for social prescribing for autistic adults. I'm not sure how useful it is as a standalone section.

d) The recommendation on sensory questionnaires was very specific and it is unclear why a questionnaire for sensory sensitivities is mentioned, rather than getting broader information about the strengths/challenges that the individual experiences in a range of areas (as per most service 'passports' or 'toolkits').

e) Service passports were recommended, and I was surprised that the healthcare toolkit of the AASPIRE team (Nicolaidis et al., 2016) ${ }^{5}$ was not mentioned, given that this is one of the few with an established evidence-base behind it.

\section{Conclusion}

To conclude, social prescribing for autistic adults is a crucially important topic, and I believe that this letter has the potential to be not only well-cited, but also an essential resource for service providers in designing accessible, respectful and person-centred social prescribing services for autistic adults. I hope the authors find these comments helpful and that, more importantly, this letter becomes a catalyst for the development of research and practice on effective social prescribing services for autistic adults.

\section{References}

1. Bickerdike $L$, Booth A, Wilson P, Farley K, et al.: Social prescribing: less rhetoric and more reality. A systematic review of the evidence. BMJ Open. 2017; 7 (4). Publisher Full Text

2. Crane L, Hearst C, Ashworth M, Davies J, et al.: Supporting Newly Identified or Diagnosed Autistic Adults: An Initial Evaluation of an Autistic-Led Programme.J Autism Dev Disord. 2020. PubMed Abstract | Publisher Full Text

3. Crompton CJ, Hallett S, Ropar D, Flynn E, et al.: 'I never realised everybody felt as happy as I do when I am around autistic people': A thematic analysis of autistic adults' relationships with autistic and neurotypical friends and family.Autism. 2020. 1362361320908976 PubMed Abstract | Publisher Full Text

4. Crane L, Adams F, Harper G, Welch J, et al.: 'Something needs to change': Mental health experiences of young autistic adults in England.Autism. 23 (2): 477-493 PubMed Abstract I Publisher Full Text

5. Nicolaidis C, Raymaker D, McDonald K, Kapp S, et al.: The Development and Evaluation of an Online Healthcare Toolkit for Autistic Adults and their Primary Care Providers.J Gen Intern Med. 31 (10): 1180-9 PubMed Abstract | Publisher Full Text 
6. Nicolaidis C, Raymaker DM, Ashkenazy E, McDonald KE, et al.: "Respect the way I need to communicate with you": Healthcare experiences of adults on the autism spectrum.Autism. 2015; 19 (7): 824-31 PubMed Abstract | Publisher Full Text

Competing Interests: I have cited two of my own papers in my review. Whilst I do not expect the authors to cite these in any revision of their work, they do seem very relevant to the topic of their letter.

Reviewer Expertise: autism, education, healthcare (diagnosis, mental health), participatory research

\section{I confirm that I have read this submission and believe that I have an appropriate level of expertise to confirm that it is of an acceptable scientific standard, however I have significant reservations, as outlined above.}

Author Response 29 Jan 2021

Rebecca Charlton, Goldsmiths University of London, London, UK

\section{Response to Reviewer 1}

We thank the reviewer for their encouragement and insightful comments.

We acknowledge the reviewer's point that the paper could omit or reduce the overview of Social Prescribing for the general population and focus exclusively on autistic individuals. The rationale for including information on the general population is two-fold. Firstly, while there are many activities and groups offering support that could be offered by Social Prescribing, few of these have been delivered formally as Social Prescribing or evaluated within that context, and none exclusively to autistic adults. We have clarified this point and made clear distinction between evidence from contained activities and support, and the lack of those offered as part of Social Prescribing. Given the paucity of studies, information from the general population is important to consider. Secondly, although the focus of this paper is how Social Prescribing could be applied to support autistic adults, much of the review is more broadly relevant and can be applied to and by other charities. The choice of journal was made to allow this reflection on Social Prescribing to reach a wide audience, therefore the decision to include a wider literature. Another limitation to the suggested reformatting of the paper and inclusion of recommendations, is that there is currently little evidence to support such recommendations. Without proper evaluations of Social Prescribing we do not feel able to recommend "best practice". However we have included reference to a range of resources (we have also added the Healthcare toolkit, many thanks for the recommendation) that will be relevant to a wide range of Social Prescribing services for both autistic and non-autistic adults. It is hoped that this paper, written at the beginning of a national Social Prescribing launch will raise awareness of the need for proper evaluations, leading to future recommendations. We have added text to the Letter clarifying these points.

Regarding the very interesting point about whether Social Prescribing services should be autism-specific. We do not necessarily advocate that services should be autism-specific for several reasons. Firstly, we think it is important to note that many autistic adults have multiple complex needs, as well as differences in ability, interests, and functional strengths 
and weaknesses. Being realistic about the likely availability of provision within different local communities, a non-autism specific service may offer the best support for an individual, and would be preferable to an autistic adult either receiving no support or needing to travel a large distance for an autism-specific provision. Furthermore, although a number of studies have found that services led by autistic individuals can be beneficial for autistic adult outcomes, many authors have also commented on the need to avoid isolating autistic adults into silos. Therefore we would suggest that general services which accept and support neurodiversity will have the greatest impact. Indeed, the purpose of this paper was to raise awareness of the need for Social Prescribing services to be designed or adapted to include autistic adults in the face of the recent change to NHS Universal Personalised Care. We have included a comment reflecting these points in the text, and referenced the support that both autistic individuals and organisations advocating for autistic adults can offer to create appropriate services.

Executive function and sensory sensitivities are discussed as they may lead to specific barriers to accessing services. Sensory sensitivities are described in more detail as an example of how specific autistic characteristics may make accessing services difficult, and where service adjustments could have a positive impact on accessibility. We have clarified these points.

A definition of Social Prescribing is at the beginning of the second paragraph in the General Statement section, and also (more succinctly) in the abstract.

We have updated the literature review to include a number of papers including a systematic review of Social Prescribing (Pescheny et al., 2020) and (as suggested by the reviewer) papers by Nicoladis et al., 2016.

Competing Interests: No competing interests were disclosed. 